\title{
Design and optimization of the pipe fixed supports in the super high-rise building
}

\author{
Ye Huang ${ }^{1, ~ a}$, Hehui Wang ${ }^{2, b}$, Xinyu Hü ${ }^{1, c}$, Yan $\mathrm{Li}^{1, \mathrm{~d}}$, Zhihua Wang ${ }^{2, \mathrm{e}}$ \\ ${ }^{1}$ General Construction Company of CCTEB Group CO.,LTD, Wuhan, 430064,China; \\ ${ }^{2}$ School of Mechanical and Power Engineering, East China University of Science and Technology, \\ Shanghai, 200237, China \\ ahy0982@vip.163.com, bhhwang@ecust.edu.cn, ${ }^{\mathrm{c}} 18086639570 @ 189 . c n$, \\ d18986078853@163.com, ${ }^{\mathrm{e} w z h h 910312 @ 163 . c o m}$
}

\begin{abstract}
Keywords: Super high-rise building; Multi-layer supports; Finite element analysis; Lug-support.
Abstract. The finite element (FE) technique is applied to conducting the strength design and optimization of the vertical pipe fixed supports in a super high-rise building. The FE model of the fixed support is created and the stress distributions are calculated by using ANSYS. In this paper a new method is given to install the fixed supports by multi-layers. Lug-supports are welded on the locations where large stress is high so that the stress can be decreased and the overall structure has certain strength. These methods can apply as instructions for the design of the pipe fixed supports of the vertical pipelings in super high-rise buildings.
\end{abstract}

\section{Introduction}

With the rapid development of the comprehensive strength of China's economy, more and more high-rise buildings appear in most domestic cities. At present, the construction period of high-rise buildings is usually short and the design time is generally not too abundant[1], so many various technical problems about them also emerged. The high-rise buildings usually have the characteristics like high floor, great circulating cooling water, big pipe, long pipeline and limited building space, etc,[2] which bring difficulties and challenges for the design of pipe supports. In the water supply and drainage projects of high-rise buildings, most pipes are arranged vertically through tube wells. To ensure these vertical pipes can install and run safely and reliably, it is necessary to set up several fixed supports[3]. Whether the design of the pipe fixed supports is reasonable will directly affect the cost of the project, the forces on the pipes and the reliability of the whole system. Therefore, appropriate design and optimization is necessary to the pipe supports in super high-rise buildings for the sake of improving the safe reliability.

\section{Loads analysis of the fixed support}

This paper manily focuses on the three air conditioning cold and hot vertical water pipes of 117 building in Tianjin. The height of the vertical pipes in this building is relatively high and the gravity of whole water and the pipes own weight can pose a big pressure on the bottom of pipe bends due to the large diameter pipe. To ensure the security of the entire circulating water piping system, the fixed pipe support must be set up at appropriate position of the floor to support the three pipes. The overall structure of the fixed supports and pipes in the building is shown in Fig.1. 


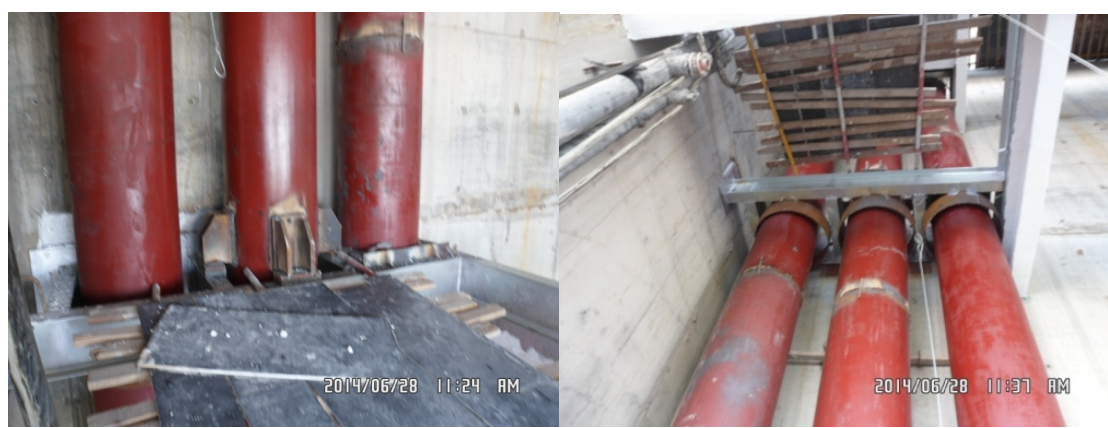

Fig.1 The scene photos of the fixed supports and pipes

The three pipes in Fig. 1 are supply pipe, reserve pipe and return pipe. To calculate the maximum load of the fixed supports, supposing the three DN700 pipes are both all filled with water and all loads on the supports must be considered. The design loads mainly include three parts: pipes' own gravity, the pressure generated by water in pipes, flexible joint's elastic force. The material of these pipes is 20\# low-carbon steel. The density $\rho$ is $7850 \mathrm{~kg} / \mathrm{m}^{3}$. The outside diameter , thickness and length of these pipes are $711 \mathrm{~mm}, 16 \mathrm{~mm}$ and $76.72 \mathrm{~m}$. Due to the need of keeping warm, every pipe is covered with a certain thickness of rubber insulation, but the rubber's weight takes little proportion in the total loads, so the effect of rubber insulation could be ignored. According to all of these conditions, the value of single pipe's gravity $\mathrm{G}$ and the pressure $\mathrm{F}_{\mathrm{p}}$ on the pipes' bends can be calculated. Since the adjacent two floors of fixed supports limits the thermal deformation of pipeline, the thermal stress occurs in pipes. When the temperature changes $\Delta \mathrm{T}$, thermal deformation generate in the pipes[4].

$$
\Delta \mathrm{l}=\alpha \mathrm{l} \Delta \mathrm{T} .
$$

In this equation $\alpha$ is linear expansion coefficient, 1 is the distance of two adjacent floors of fixed supports, $\Delta \mathrm{T}$ is the maximum temperature difference. The maximum thermal stress can be calculated according to equation (2)

$$
\sigma_{\mathrm{T}}=\alpha \mathrm{E} \Delta \mathrm{T} .
$$

Here $\mathrm{E}$ is the Young modulus. The vertical height from the fixed support in the 6th floor to the bellows in the 12th floor is $27.45 \mathrm{~m}$, so the maximum axial thermal deformation of the pipe generated by the temperature difference is $10.414 \mathrm{~mm}$. The deformation is mainly compensated by the bellows and its stiffness is $4000 \mathrm{~N} / \mathrm{mm}$. So the bellows' elastic force $F_{b}$ is also calculated.Loads generated by a single pipe can be calculated by the follow equation

$$
\mathrm{F}_{\text {total }}=\mathrm{F}_{\mathrm{p}}+\mathrm{G}+\mathrm{F}_{\mathrm{b}}=1156736 \mathrm{~N} \text {. }
$$

Through the result calculated in the equation (3), the method that the fixed support set at single layer has not meet the strength requirements. Given that the heat distortion of pipes between adjacent layers is small and the distortion could be counteracted by self deformation of the fixed supports, the design of three layers combined fixed supports are present. In order to solve the problem of insufficient support strength, double plate reinforced and strengthened type bracket are also be present. Because the multi-layers combined fixed supports are generally not more than three layers, three fixed supports are set at the 3th, 4Mth, 4th floors to support the pipes on both sides and two fixed supports are set at the 5th, 6th floors to support the middle pipe. By this way, the total load can be distributed on different supports instead of concentrating on a floor support and the strength of the fixed support can also be improved greatly. 


\section{FE simulation of the fixed support}

Ansys modeling. In order to research the stress intensity of the fixed support, finite element method is used in this paper. Pipeline and its supporting system shall be simulated and optimized by Ansys. The fixed support model includes two main beams and three vice beams. They are welded together with the embedded iron in the wall. The type of these beams is 36C I-steel. Fig.2 shows the 3D models of the fixed supports and pipes in different floors.

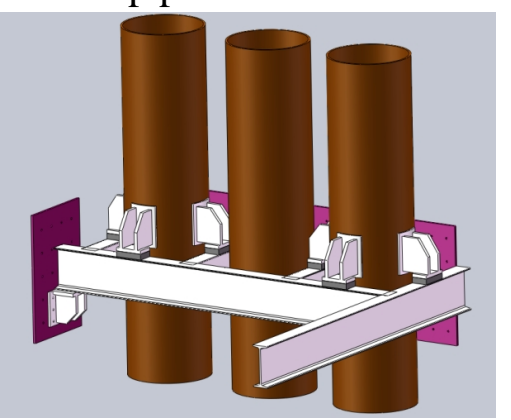

(a) Fixed support in the $3^{\text {th }}, 4 \mathrm{M}^{\text {th }}, 4^{\text {th }}$ floors

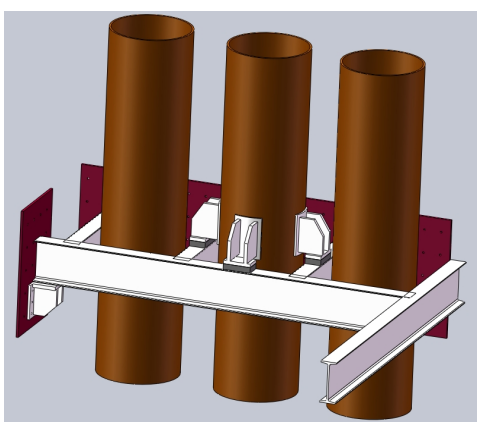

(b) Fixed support in the $5^{\text {th }}, 6^{\text {th }}$ floors

Fig.2 3D model of the Multi-layer fixed support

Element BEAM189 is used in the process of establishing the fixed support model (Fig.2). The

BEAM189 element is suitable for analyzing slender to moderately stubby/thick beam structures. The element is based on Timoshenko beam theory which includes shear-deformation effects and it provides options for unrestrained warping and restrained warping of cross-sections[5]. During the process of modeling, the main beam B is not included. According to the practical situation in spot, there are steel beams to support beam $B$ and concrete is poured into the space between steel beam and the main beam $\mathrm{B}$. Therefore, it can be considered that the actual intensity of the main beam B is as twice much as $36 \mathrm{C}$ and compressive property is very good. The strength and stiffness of main beam B are far more than other beams, so it could be ignored during the stress analysis.

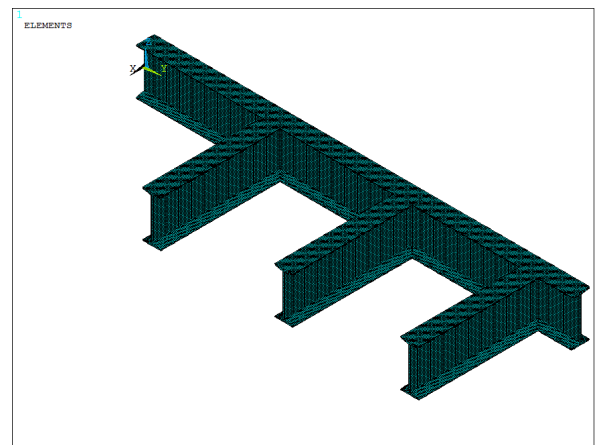

Fig.3 Finite element meshes of the fixed support

The FEA software Ansys will be used for the detailed stress analysis. For the fixed support model, the nodes at the end of all beams are fully fixed. The total loads generated by the pipe system are applied to the beams as uniform load.

Stress analysis results. Considering the influence of weld residual stress in heat affected zone, the allowable stress of the weld need to test strictly. Refer to the strength design of pressure vessel and piping system, the weld reduction factor $(0.5)$ is considered in this paper. Table. 1 shows the allowable stress of 20\# steel at different positions.

Table.1 Allowable stress of 20\# steel [MPa]

\begin{tabular}{ccc}
\hline & allowable bending stress & allowable shear stress \\
\hline 20\# steel & 131 & 65.5 \\
\hline weld seam & 65.5 & 32.75 \\
\hline
\end{tabular}




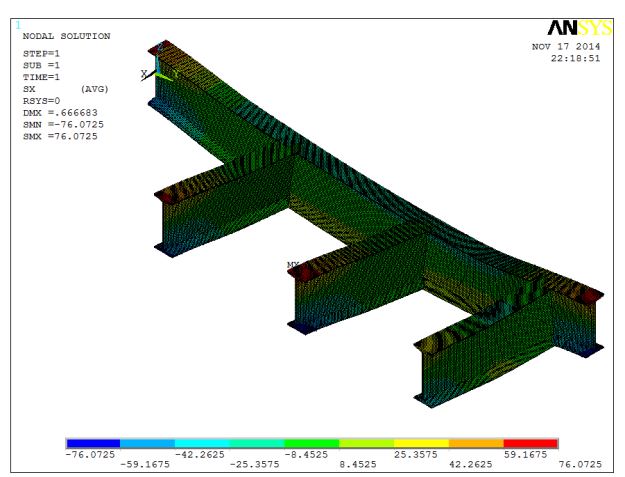

(a)Contour of bending stress in the $3^{\text {th }}, 4 \mathrm{M}^{\text {th }}, 4^{\text {th }}$ floors

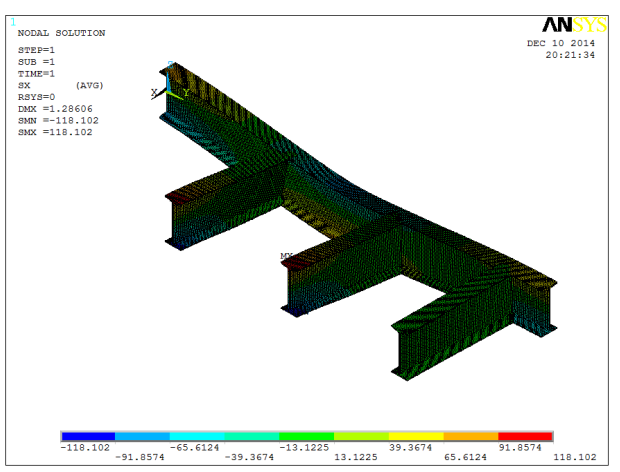

(b)Contour of bending stress in the $5^{\text {th }}, 6^{\text {th }}$ floors

Fig. 4 Contour of bending stress of the fixed support

As shown in the Fig.4, in the 3th,4Mth,4th floors, the maximum stress, $76 \mathrm{MPa}$, which exceed the allowable bending stress, $65.5 \mathrm{MPa}$, occurs at the end of the middle vice beam. In the 5 th, 6 th floors, the maximum stress, $118.1 \mathrm{MPa}$, which also exceed the allowable bending stress, occurs at the same position.

Optimization of the fixed supports. On the basis of the FEA results, the level of maximum stress at the end of vice beam is higher than those of other position. In view of this condition, the concrete measures of consolidation and reinforcement for the supports must be taken so as to ensure the safety of the pipe systems. The main method is by welding lug-support at the end of each vice beam. In order to reflect the effect of lug-support in the Ansys analysis process, the nodes at the lug-support are all DOF.

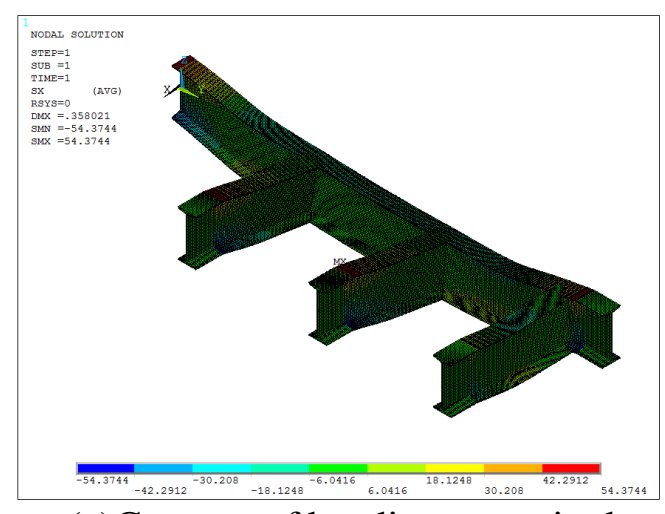

(a)Contour of bending stress in the

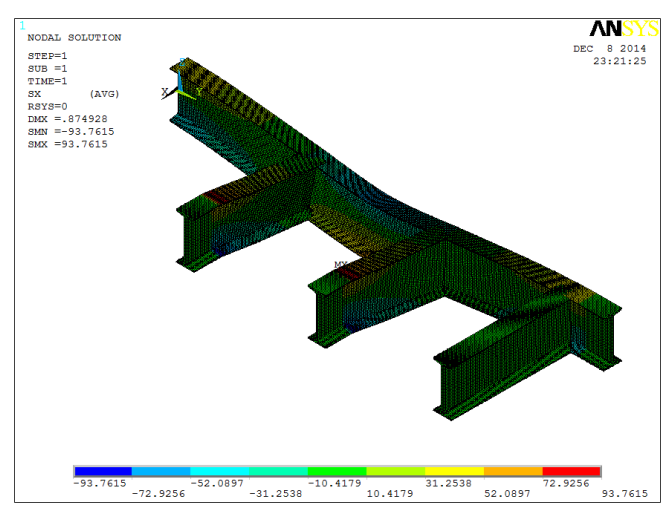

(b) Contour of bending stress in the

3th,4Mth,4th floors after welding lug-support $\quad 5^{\text {th }}, 6^{\text {th }}$ floors after welding lug-support
Fig. 5 Contour of bending stress of the fixed support after welding lug-support The bending stress distribution of the fixed support after welding lug-support is shown in Fig.5. The maximum bending stress , $54.3744 \mathrm{MPa}$ and $93.7615 \mathrm{MPa}$, is lower than before. The lower rate could reach $28.5 \%$ and $20.6 \%$ respectively. The results indicate that the lug-support has better enhancing effect than the original approaches.

Table.2 Stress comparison analysis of 3th,4Mth,4th floor[MPa]

\begin{tabular}{lcccc}
\hline & \multicolumn{2}{c}{ No lug-support } & \multicolumn{2}{c}{ lug-support } \\
\hline & $\begin{array}{c}\text { maximum bending } \\
\text { stress }\end{array}$ & $\begin{array}{c}\text { maximum shearing } \\
\text { stress }\end{array}$ & $\begin{array}{c}\text { maximum bending } \\
\text { stress }\end{array}$ & $\begin{array}{c}\text { maximum shearing } \\
\text { stress }\end{array}$ \\
\hline Main beamA & 71.40 & 29.26 & 29.76 & 4.07 \\
\hline Vice beam 1 & 36.38 & 21.59 & 15.17 & 3.34 \\
\hline Vice beam 2 & 76.07 & 29.83 & 31.69 & 4.65 \\
\hline Vice beam 3 & 65.57 & 27.65 & 27.32 & 4.57 \\
\hline
\end{tabular}


Table. 3 Stress comparison analysis of $5^{\text {th }}, 6^{\text {th }}$ floor $[\mathrm{MPa}]$

\begin{tabular}{ccccc}
\hline & \multicolumn{2}{c}{ No lug-support } & \multicolumn{2}{c}{ lug-support } \\
\hline & $\begin{array}{c}\text { maximum bending } \\
\text { stress }\end{array}$ & $\begin{array}{c}\text { maximum shearing } \\
\text { stress }\end{array}$ & $\begin{array}{c}\text { maximum bending } \\
\text { stress }\end{array}$ & $\begin{array}{c}\text { maximum shearing } \\
\text { stress }\end{array}$ \\
\hline $\begin{array}{c}\text { Main } \\
\text { beamA }\end{array}$ & 63.22 & 12.83 & 19.65 & 1.54 \\
\hline $\begin{array}{c}\text { Vice } \\
\text { beam 2 }\end{array}$ & 118.10 & 46.06 & 39.07 & 7.53 \\
\hline $\begin{array}{c}\text { Vice } \\
\text { beam 3 }\end{array}$ & 109.66 & 44.30 & 38.64 & 7.49 \\
\hline
\end{tabular}

The maximum stress comparison before and after welding lug-supports is shown in Table 2 and Table 3. After welding lug-supports, maximum bending stress of these beams decreased obviously, not beyond the allowable bending stress.

\section{Conclusions}

Since the pipe system in high-rise building is real complex and the strict requirement for the pipe supports, the problem of pipe supports' strength must be put enough attention. Loads analysis and numerical simulations of finite elements are presented on the supporting system. Based on the FEA results, this paper presents a new method that fixed supports are arranged at multi-layers to support the whole pipeline. Welding lug-supports at where the maximum stress occurs is also a innovation point. Numerical results show that there is a significantly reduced stress at key locations and the overall structure has certain strength. These innovative methods can apply as instructions and reference for the design and installation of the pipe supports.

\section{References}

[1] Yang ZhiGang, LiuChangSha. Design of the pipe supports in high-rise building tube wells[J]. Installation, 2012, ( 10 ) : 45-47(In Chinese).

[2] Yu XinGuo. Pipe support design of DN700 cooling water circulation in high-rise building[A]. 2011 Chinese Building Water Technology Forum Proceedings[C]. 2011:193-202(In Chinese).

[3] Chen ZhenYi. Thermal compensation scheme of piping arrangement in HVAC water system[J]. Theory of Urban Construction, 2011(6)(In Chinese).

[4] Liu HongWen. Mechanics of Materials I[M]. 4th ed. Beijing: Advanced Education Press, 2010:151-152(In Chinese).

[5] Liu Wei, Gao WeiCheng, Yu GuangBin. ANSYS12.0 Bible[M]. Beijing: Publishing House of Electronics Industry, 2010:206-234(In Chinese). 